\title{
A dimensão humana do trabalho e do desemprego: uma análise do filme "O adversário"
}

\author{
Vander Casaqui \\ Professor do Mestrado em Comunicação e Práticas de Consumo - ESPM. \\ vcasaqui@espm.br
}

\begin{abstract}
Resumo:
Este trabalho tem por objetivo analisar o filme francês "O adversário" (2002, direção de Nicole Garcia, com Daniel Auteuil), que apresenta no centro da narrativa uma reflexão crítica sobre os encadeamentos entre o mundo do trabalho, o desemprego e a produção de subjetividade. Os choques entre a dimensão humana e a econômica, entre desejo e determinismo, caracteriza a trajetória do protagonista - o desempregado que esconde sua situação da família com rituais diários que simulam uma vinculação empregatícia. Por meio da análise da narrativa audiovisual, buscamos compreender os significados do mundo do trabalho e do desemprego na produção cinematográfica - esta entendida como uma forma privilegiada de materializar pontos de vista sobre a condição humana em meio ao contexto sócio-cultural-econômico de nosso tempo.
\end{abstract}

Palavras-chave: Comunicação e consumo, mundo do trabalho, cinema, linguagem.

\begin{abstract}
:
This paper aims to analyze the french movie "The adversary" (2002, directed by Nicole Garcia, with Daniel Auteuil), that presents in the center of the narrative a critical reflection on the linkages between the world of work, unemployment and the production of subjectivity. Clashes between human and economic dimensions, between desire and determinism characterize the trajectory of the protagonist - the unemployed who hides from his family his real situation with daily rituals that simulate a binding job. Through the analysis of the audiovisual narrative, we learn the meanings of the world of work and unemployment in film production - this being understood as a privileged form to materialize points of view on the human condition amidst the sociocultural-economic development of our time.
\end{abstract}

Keywords: Communication and consumption, work, movies, language.

O mundo do trabalho é uma das esferas fundamentais de mediação social, e nessa condição, está presente no imaginário, transmutando-se de acordo com cada época, com os aparatos tecnológicos disponíveis, com o caráter das relações humanas, no contexto mais amplo em que a atividade laboral se insere. Nesse sentido, a circulação social do trabalho como signo reflete e refrata (Bakhtin, 1997) os embates ideológicos de cada momento histórico. Materializado em narrativas, em linguagem, o trabalho é associado a visões de mundo, expressando inquietações que dizem respeito ao cenário histórico em que os produtos culturais são concebidos. Nesse sentido, a leitura das representações sociais presentes na trama cinematográfica permite o acesso a um mundo editado em torno dos problemas, dos impasses, das esperanças, dos valores humanos postos em cena: 
O cinema é, pois, o mundo, mas um mundo meio assimilado pelo espírito humano. Assim como também é o espírito humano, mas projectado, activamente, no mundo, no seu trabalho de elaboração $e$ de transformação, de permuta e de assimilação. A sua dupla e sincrética natureza, objectiva e subjectiva, acaba por desvendar-nos a sua secreta essência, ou seja, a função e o funcionamento do espírito humano no mundo. O cinema mostra-nos, pois, o processo de penetração do homem no mundo e o inseparável processo de penetração do mundo no homem (MORIN, 1997: 232-3).

Morin destaca a forma como os sujeitos percebem a realidade como duplo vínculo, objetivo e subjetivo, como realidade concreta e como ficção, sem que haja fronteiras estanques que delimitam cada uma dessas faces da natureza humana. Dessa forma, o cinema está entranhado no cotidiano, compondo cenários em que os espectadores reconhecem elementos que estão presentes em sua vida, e simultaneamente narrativiza a ação humana para oferecer de volta a possibilidade de o observador projetar sua existência na trama cinematográfica e refletir sobre ela. $\mathrm{O}$ espírito humano se transmuta em ação, em representação - o cinema, pois, para além do mero entretenimento, tem o poder de materializar em signos a essência do homem:

O imaginário é o fermento do trabalho do eu sobre si próprio e sobre a natureza, através do qual se constrói e desenvolve a realidade do homem. Assim, não se pode dissociar o imaginário da "natureza humana" - do homem material. Ele é sua parte integrante e vital. Contribui para a sua formação prática. É o verdadeiro alicerce de projecções-identificações, a partir do qual o homem, ao mesmo tempo que se mascara, se conhece e se constrói (MORIN, 1997: 236).

A partir de Morin, compreendemos que o trabalho transcende a mercadorização da atividade humana por meio da divisão científica do trabalho, e que a transformação de si é sua essência, como já apontava Marx, tese sobre a qual Morin acresce a idéia de que o imaginário alimenta as práticas humanas e as mobilizam como não concordar com o autor, quando consideramos, por exemplo, o ideário da modernidade, em torno da ordem e do progresso, do desejo de controle e da ruptura com as tradições, da intervenção do homem sobre a natureza para dominá-la e edificar o futuro, e como esse ideário deu sentido às práticas cotidianas de sua época, à concepção das técnicas e das ferramentas, aos projetos e ações que caracterizaram o espírito nacional, entre outros aspectos do homem em ação a compor o mundo ao seu redor? Nesse sentido, o trabalho a partir da capacidade de imaginar caracteriza o ser humano. O cinema pode ser combustível da atividade dos sujeitos em relação a si mesmos e ao mundo que os rodeia, nos processos complementares e intercambiáveis de produção e consumo em suas várias dimensões: o consumo cultural e o midiático, dessa forma, servem à produção de si que estabelece conexões com as homologias entre produção e consumo - como bem aponta Bourdieu (2007: 215-217). Segundo o autor, a percepção das "necessidades" e "desejos" e a formação do gosto do consumidor, aquilo que se insinua como sonho de consumo, de certa forma, está calcado nas possibilidades da produção de seu tempo, naquilo que o mercado oferece e no imaginário que alimenta as possibilidades da produção. Por outro lado, o trabalho em torno da produção de bens e ofertas de serviços é baseado naquilo que é demandado pelos consumidores, na forma como a vida social, as interações entre os homens, os diversos cenários pelos quais transitam são percebidos como oportunidades de mercadorização da experiência humana. 


\title{
Visões do trabalho, do consumo e do desemprego
}

A questão do desemprego tem espaço na pauta midiática relativa ao capitalismo global de maneira recorrente. Toda crise econômica tem como impacto mais evidente o corte de funcionários, e mesmo em tempos de aparente estabilidade, os movimentos migratórios, a incapacidade da economia de contemplar todos os cidadãos com postos de trabalho, enfim, o déficit de vagas - que parece ser inerente à economia de mercado - alimenta essa categoria que identifica negativamente multidões, cuja existência fica à margem das benesses da sociabilidade baseada no consumo e que está vinculada a um momento histórico bem demarcado:

\begin{abstract}
O desemprego é uma forma histórica, pertence a uma época e a um lugar e, como reconhecido desde Ledrut, é uma situação própria a uma certa condição econômica: aquela do trabalhador assalariado. A substituição da qualificação "falta de trabalho" pela categoria de desemprego decorre da codificação da relação salarial. Até o início do século XIX, chômer designava uma interrupção de atividade que acarretava a perda do salário por qualquer motivo (um dia de folga é um dia sem trabalho nem salário). O termo "desemprego" (utilizado em sua forma verbal) tinha então uma extensão muito grande e uma significação muito mais ampla do que hoje. (...) Ora, a codificação das relações de trabalho na relação assalariado-empregador acompanha a racionalização e a mecanização da produção industrial. De fato, essas transformações do trabalho levam a autonomizar um tempo do trabalho, isolado das outras atividades, separado no emprego do tempo dos indivíduos, mensurável e controlável. Os empregadores podem então regular e aplainar o volume de trabalho, isolar um excedente, e eliminar os indivíduos menos produtivos, reduzir seus efetivos, demitir (DEMAZIÈRE, 2006: 27-8).
\end{abstract}

Da mesma forma, o valor do trabalho reconhecido socialmente se transforma com o tempo: no momento em que vivemos, a centralidade do consumo transfere às atividades laborais vinculadas aos serviços, às tecnologias digitais, ao uso da criatividade, entre outros atributos, certa aura que a distingue do trabalho industrial, outrora tido como símbolo de uma era de progresso. Na história do século XX, são inúmeros os exemplos da utilização da imagem do trabalhador industrial nas estratégias de propaganda de governos totalitários, nacionalistas, "revolucionários": de Hitler a Stálin, de Vargas a JK, os significados dessa imagem ancoraram a retórica do progresso no cotidiano do povo, revestindo o esforço de cada um, representado pelas cenas mitificadas pela comunicação visual e audiovisual que tinha por função mobilizar os sujeitos para dar força e legitimidade a governantes, ideologias, nações - o que ainda acontece, mas sem a mesma força de outros tempos. Como defende Lazzarato,

O trabalho industrial não é mais o centro da valorização capitalista, nem um modelo de subjetivação política e social válido para o conjunto das forças sociais, tampouco a única força capaz de produzir as instituições e uma politização das sociedades de controle. Nos países ocidentais, o assalariamento permanece sendo a forma dominante sob a qual o capitalismo explora a cooperação e o poder de invenção das subjetividades quaisquer, mas explodiu em uma multiplicidade de atividades e de estatutos que se exprimem por subjetividades e demandas que não podem mais ser reportadas ao conceito tradicional de classe (LAZZARATO, 2006: 88). 
As relações entre produção e consumo ganham contornos mais complexos quando nos voltamos à figura do trabalhador, nesse contexto contemporâneo em que as atividades ligadas a serviços requerem de quem as exerce um envolvimento mais intenso de sua subjetividade, de sua capacidade de comunicação e de convencimento, de seu contato direto com o consumidor. Essas interações se dão a partir da esfera de mediação que é o espaço do consumo, onde o trabalho ganha contornos de estetização, como bem aponta Haug (1997): o vendedor comunica a estética da mercadoria e, simultaneamente, faz parte dela, no processo de atribuição de sentido ao que é ofertado ao consumidor. Porém, esse fenômeno que poderia ser entendido como restrito ao trabalhador que tem por função o contato direto com os clientes, em sentido amplo (os chamados stakeholders), na cultura organizacional contemporânea atinge todos os níveis de produtores. Daí que os processos comunicacionais que envolvem a organização se voltam estrategicamente tanto a consumidores quanto aos produtores, para que esse mundo editado pela corporação seja incorporado por ambos:

\begin{abstract}
A empresa que produz um serviço ou uma mercadoria cria um mundo. Nessa lógica, o serviço ou o produto - da mesma maneira que o consumidor e o produtor - devem corresponder a este mundo. Este último precisa estar inserido nas almas e nos corpos dos trabalhadores e dos consumidores. Tal inserção se faz através de técnicas que não são mais exclusivamente disciplinares. No capitalismo contemporâneo, a empresa não existe fora do produtor e do consumidor que a representam. $\mathrm{O}$ mundo da empresa, sua objetividade, sua realidade, confunde-se com as relações que a empresa, os trabalhadores e os consumidores têm entre si. Trata-se então de tentar estabelecer correspondências, entrelaçamentos, acoplamentos entre mônadas (consumidor e trabalhador) e mundo (a empresa) (LAZZARATO, 2006: 99).
\end{abstract}

O sentido da produção, a partir da idéia do mundo construído pela corporação, expande-se para assimilar o que é derivado dos processos comunicacionais que envolvem a construção desse mundo. Nesse contexto realiza-se a produção de consumidores (GORZ, 2005: 48), que corresponde a uma etapa fundamental da circulação da mercadoria: como vimos anteriormente a partir de Bourdieu, a homologia entre produção e consumo tem como consequência a instauração de sujeitos como consumidores a partir das ofertas do mercado. Da mesma forma, o trabalhador produz a si mesmo através de sua atividade, tanto quanto é produzido pela instância mediadora da empresa para a qual fornece sua força de trabalho em troca de remuneração, de seu salário. Ambos, trabalhadores e consumidores, por caminhos complexos, representam a corporação nos cenários sociais em que se inserem - nesse sentido, as estratégias corporativas têm um viés totalizante (em alguns casos, poderíamos dizer totalitário) que no projeto desse mundo construído ambiciona o controle das subjetividades como forma de legitimar a imagem de si transmitida pelo outro, ou seja, pelo trabalhador e pelo consumidor que expressariam os valores corporativos, ao passo em que se instauram como sujeitos da comunicação. Vemos aqui ecos do "discurso competente" (CHAUÍ, 1980), como analisamos em estudo realizado a partir dos discursos midiáticos do Google (CASAQUI e RIEGEL, 2009), nos quais as falas dos googlers, os trabalhadores da empresa que tem o famoso serviço de buscas da Internet como carro-chefe de seus negócios, são a expressão tornada mais visível na estratégia de transmitir a imagem da marca Google. A 
"evangelização" é o termo utilizado na cultura da empresa para exprimir a ambição de unir trabalhadores e consumidores em um mesmo movimento de fidelização, de alinhamento aos "valores" do Google. O discurso religioso permeia a cultura organizacional em muitos sentidos, eis um exemplo dos mais evidentes.

No cenário de crise do emprego, a construção da identidade a partir do trabalho entra em conflito, e o consumo migra da esfera da realização material de afetos para o plano das ausências, das frustrações e pressões sociais. O desemprego passa a ser um fantasma para um enorme contingente de trabalhadores, e uma realidade terrível para tantos outros. Como diz Dubar, em estudo sobre o contexto francês,

A identidade pessoal é tão inseparável da trajetória profissional, do sentido da atividade na duração de uma vida, das oportunidades de se formar, de progredir, de ter acesso a atividades qualificadoras, como das convicções e dos engajamentos políticos, de sua evolução ao longo da vida toda. Essa construção identitária é, portanto, tanto uma questão eminentemente privada quanto uma questão pública e, portanto, política, no sentido mais forte. Como cidadão, ou simplesmente como ser humano, cada um deve poder encontrar recursos para construir sua identidade pessoal, inclusive recursos simbólicos que lhe permitam alcançar a cidadania (DUBAR, 2009: 191-192).

Através da análise do filme "O adversário", que traz ao centro de sua narrativa o tema dos impasses dos personagens diante da questão do desemprego, refletimos acerca da esfera da atividade laboral humana e seus significados.

\section{"O adversário" e a tragédia "real" em torno do desemprego}

O filme "O adversário" (2002) é uma produção francesa que traduz a obra literária de Emmanuel Carrère, que por sua vez narrativiza o acontecimento que ganhou ampla repercussão midiática em seu país: o caso em torno de Jean-Claude Romand, o homem que sustentou uma farsa durante cerca de 18 anos: estudante de medicina, no segundo ano de seu curso não prestou os exames, logo, não pode se formar. Para aqueles que estavam à sua volta, amigos, namorada (que depois se tornou sua esposa), família, ele não somente se formara como médico, mas tempos depois conseguira um prestigioso cargo de pesquisador na Organização Mundial de Saúde. A rotina de Jean-Claude se sustentava em um ritual, que na realidade, se caracterizava como simulação de sua condição: saía todos os dias para o trabalho, no mesmo horário, vestia-se de acordo com a posição que dizia ocupar, voltava para casa à noite com histórias, situações, nomes que alimentavam a verossimilhança de seu teatro. Durante o dia, passava horas em seu automóvel, em estacionamentos, no próprio prédio da OMS, como visitante que se misturava ao fluxo de trabalhadores, de pesquisadores e autoridades que transitavam pelo local. Em síntese, vivia o mundo corporativo como farsa, ao se vincular a ele por meio de sua dimensão teatral, ritualística, sem compor o contingente dos produtores.

No filme em questão, Jean-Claude Romand é renomeado Jean-Marc Faure. As primeiras imagens intercalam o personagem principal, vivido pelo ator Daniel Auteil, dentro de seu carro, dirigindo em uma via, 
com legendas sobre fundo negro que ancoram a história na memória de um acontecimento midiático para, a partir daí, ficcionalizar a "realidade":

Durante 15 anos, todo mundo acreditou em Jean-Marc Faure. Sua mulher, seus pais e seus amigos. Existe algo pior do que ser desmascarado: não ser desmascarado. Este filme é inspirado em uma história real.

O tom predominantemente escuro da fotografia desde o início sinaliza o tom da narrativa cinematográfica: trata-se de um filme sombrio, que traduz para o código cromático o lado obscuro da psicologia humana (Fig.1). O efeito de realidade (BARTHES, 1994), correspondente à frase que associa a ficção com o acontecimento vivido por pessoas "reais", cujo drama tomou grande espaço nos jornais e na TV, estabelece um contrato de comunicação (CHARAUDEAU, 2007) com o observador que não é da ficção ou da fantasia, e sim da credibilidade.

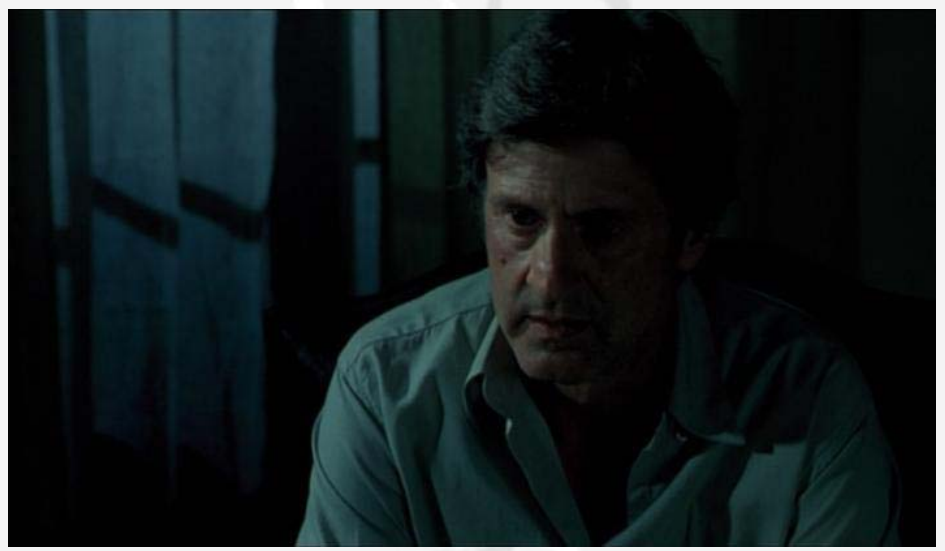

Fig.1: Jean-Marc imerso na escuridão: a fotografia do filme representa seu lado obscuro.

O cotidiano de Jean-Marc é fundado na solidão e no silêncio, uma vez que não participa de uma comunidade em torno do trabalho; pelo contrário, evita aprofundar conversas com profissionais que cruzam seu caminho, uma vez que há sempre a possibilidade de ser desmascarado. A maneira como se relaciona com o espaço configura o significado do não-lugar (AUGÉ, 1994): para o autor, se o lugar é histórico, relacional e identitário, o não-lugar é seu oposto, e se encaixa perfeitamente com as situações vividas pelo personagem em seu expediente simulado. Seu "escritório" - onde passa o tempo lendo revistas, jornais, algumas publicações e estudos que podem se relacionar à atividade que diz realizar - é o automóvel, o café, a estrada (Fig.2). Sua longa permanência nesses espaços causa certa estranheza para aqueles que o circundam. Sua introspecção e apatia impedem qualquer proximidade do outro. O tempo do trabalho se confunde com o tempo do ócio, e a experiência do não-lugar revela a lacuna na vida do sujeito sem emprego. 


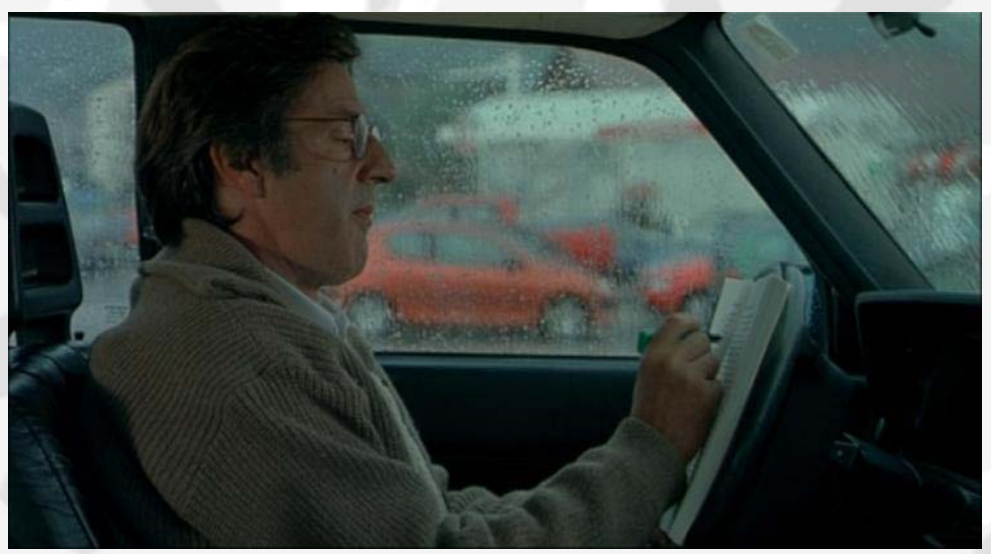

Fig. 2: Jean-Marc em sua rotina de permanecer em não-lugares como o automóvel parado no estacionamento de um supermercado.

Ao passo em que dissimula sua realidade, Jean-Marc constrói o sentido da verossimilhança por meio do consumo. Seu padrão de vida deve corresponder ao cargo que possui: quando há dissonância nessa relação entre função empregatícia e padrão de consumo, o personagem sofre a pressão da esposa e dos amigos. $\mathrm{O}$ apartamento onde mora é compreendido como incongruente em relação ao seu status, o que faz dos questionamentos das pessoas à sua volta algo mais grave do que seria normalmente, tornando-se um risco de a verdade vir à tona. O habitus de classe (BOURDIEU, 2007: 410) surge então como ameaça e como impulsionador do golpe financeiro que o protagonista aplicava em seus próprios familiares e amigos: com a história de que tinha contatos na Suíça para investimentos com grandes vantagens e envoltos em mistério, uma vez que somente Jean-Marc "sabia" onde e como as operações eram realizadas, desviava o dinheiro confiado a ele para a manutenção do padrão de consumo que dá credibilidade à sua vida inventada. Como diz Marx, no sistema capitalista, por meio do processo fetichista da mercadoria, produtor e produto perdem seu vínculo orgânico: é somente por meio do consumo, autonomizado de suas condições de produção, que o trabalhador pode adquirir os bens necessários à sua existência, como consequência da venda de sua força de trabalho como mercadoria. Diante dessa relação entre produção e consumo, o protagonista se vale da visibilidade dos sujeitos por meio dos bens de consumo para sustentar uma imagem de que ele produz, trabalha, é recompensado por sua capacidade e empenho: nesse sentido, há uma dimensão fetichista nos rituais humanos em torno das práticas de consumo.

Desde o começo da narrativa, vemos flashes em que Jean-Marc está sozinho em sua casa, mergulhado na mais intensa escuridão, com a roupa suja e desalinhada: são fragmentos dos momentos finais, do destino trágico que vai transformar radicalmente o mundo construído por ele. Nesse cenário, vemos talvez a cena mais emblemática do filme: Jean-Marc observa a si mesmo, falando em uma gravação de vídeo, na verdade, sua mensagem de despedida à família, registrada no momento em que decidiu se suicidar (Fig.3). Apresenta-se então o homem e seu duplo: ao ver-se explicando seus atos, sua vida, suas intenções, é como se o protagonista buscasse compreender seu lado obscuro, e a sucessão de fatos que levou à destruição da família executada por 
ele: não suportando a pressão que cada vez mais o acuava, especialmente quando a mulher rompe com a crença quase cega em suas explicações ao ter certeza de uma mentira que ele dissera a ela, o passo seguinte foi matar a própria mulher, os filhos e os seus pais.

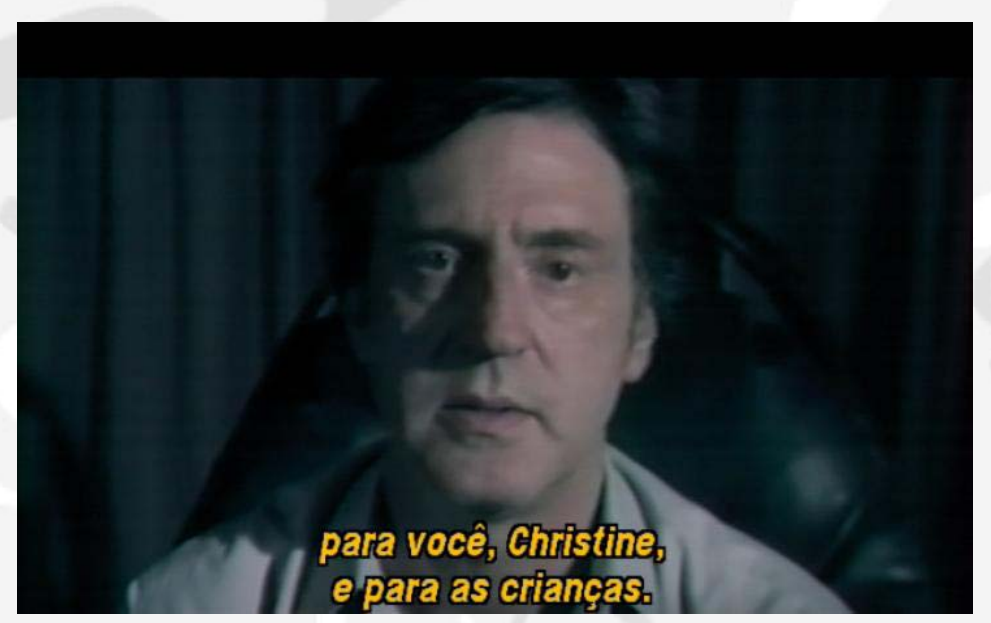

Fig. 3: Jean-Marc na tela da TV, explicando seus atos e motivações para a família.

Assim como acontece com o diálogo estabelecido na trama entre a ação do personagem e a gravação de vídeo, a narrativa é pontuada por outros entrelaçamentos, outras intertextualidades: como no momento, próximo ao desfecho da tragédia, em que Jean-Marc lê um conto infantil para seu filho. Por sabermos o final da história pela memória midiática do acontecimento, que serve também à sinopse do filme, as frases do conto, aparentemente sem relação direta com a trama principal, passam a constituir um poderoso comentário metalingüístico sobre a situação de seu protagonista.

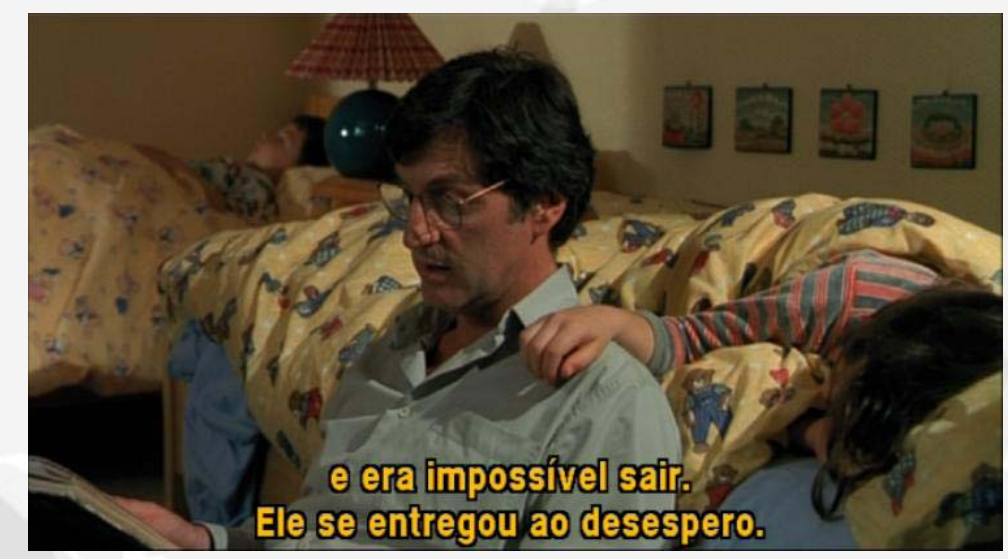

Fig.4: fragmentos do conto infantil se associam à história principal contada pelo filme.

O filme desenvolve uma curiosa relação com o conceito de trabalho estranhado de Marx (2004): ao não reconhecer-se na atividade pela qual é identificado, por ser uma dissimulação de sua verdadeira condição, Jean-Marc passa a constituir uma dimensão paralela, subterrânea em sua vida, como no caso dos golpes 
financeiros que aplica, na rotina diária, na amante que consegue e persegue insistentemente. Temos então o homem cindido, dividido, que não se identifica consigo mesmo, que se obriga a construir um teatro, uma farsa para responder às expectativas e à pressão em torno de si. Esse cenário apresenta, de maneira extrema, o significado do desemprego na vida dos sujeitos: ao não se identificar com o trabalho, o homem se torna incompleto; privado do vínculo empregatício, percebe a si mesmo como fracassado. No sentido da produção de subjetividade, que seria a função essencial do trabalho, na economia liberal em que cada sujeito é responsável pela gestão de si, com o objetivo de tornar-se "mercadoria vendável” (BAUMAN, 2008: 76), o desemprego emerge com a força da desagregação da instituição familiar, como principal motivador da subcidadania, como gerador do estranhamento dos sujeitos para consigo mesmos. Uma cena tocante que se relaciona a isso é quando Jean-Marc, após ter cometido os assassinatos de sua família, observa a jaqueta de sua esposa pendurada por um cabide junto à janela. Nesse momento, percebemos a força dos objetos, dos bens de consumo, em sua capacidade de registrar a memória das pessoas que as possuem, que as utilizam: a lembrança do outro é fortemente mediada pelos objetos que compõem o seu cotidiano e pelo qual são identificados. Nesse momento, a frieza e o calculismo do assassino dão lugar ao desespero humano: como se buscasse abrigo no ventre acolhedor da esposa que já não está mais viva, ele se ajoelha e chora, com sua cabeça encostada na jaqueta. Seu desespero revela a percepção, mesmo que tardia, da dimensão terrível do que fizera, como um momento de esclarecimento na vida mergulhada na obscuridade, no estranhamento de si.

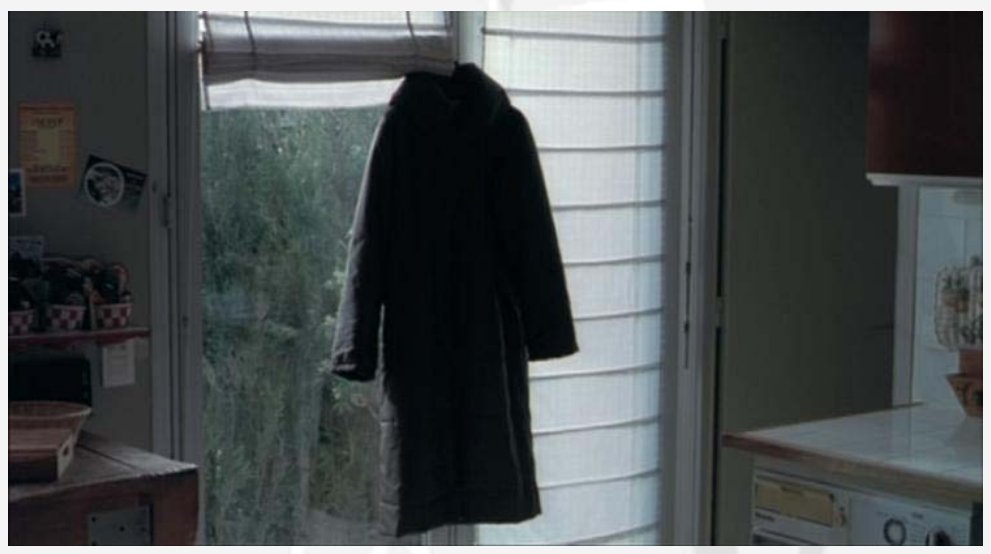

Fig.5: a jaqueta da esposa pendurada revela o poder de lembrar-se dos sujeitos a partir de seus objetos.

Jean-Marc, depois de assassinar sua esposa, seus filhos e seus pais, incendeia sua casa, porém, os bombeiros que atendem a ocorrência o encontram com vida. Na vida real, Jean-Claude Romand permanece preso pelos crimes que cometeu; na trama cinematográfica, a imagem final de uma paisagem fria e luminosa, das montanhas que remetem à infância de Jean-Marc (o lugar onde morava com seus pais), estabelece relação paradoxal com o turbilhão de acontecimentos que compõem a grande tragédia das vidas narrativizadas. A calma do cenário representa o quanto a natureza humana pode contrastar com as aparências e com os 
comportamentos socialmente aceitos e estimulados, na vida cotidiana do trabalho e do consumo. Civilização e barbárie se conectam no campo semântico do mundo do trabalho encenado pelo cinema.

\section{Considerações finais}

Através da análise do filme, procuramos identificar os sentidos do trabalho e do desemprego, no contexto da produção cinematográfica francesa recente. O panorama desenvolvido é de desesperança, em tom disfórico que passa ao plano da linguagem por meio da fotografia em tons escuros, pela escuridão como marcador da espacialidade, onde os personagens emergem constantemente. O lado obscuro da vida de JeanMichel Faure, de "O adversário", aponta para uma época em que os não ditos que permeiam as relações humanas, no cotidiano familiar, no mundo do trabalho, nas interações sociais, ganham dimensões trágicas. A dimensão ritualística que envolve o mundo do trabalho e as práticas de consumo é revelada em sua naturalização e nos conflitos sociais quando gera descompassos com as expectativas do outro.

As atribuições da responsabilidade da gestão de si mesmos (BAUMAN, 2008) aos sujeitos, aos quais são atribuídos os louros do sucesso e as culpas do fracasso, fazem do desemprego uma espécie de chaga, um atestado de incapacidade, de incompetência que diz respeito a quem é por ele atingido. Em meio aos discursos eufóricos da sociedade de consumo, o imaginário sustentado pela obra, que traduz um acontecimento "real" que ocupou grande espaço na mídia francesa à sua época, aponta para o temor diante das possibilidades de desagregação humana relativas às pressões do mundo do trabalho, às situações do desemprego e às expectativas frustradas de posse de bens de consumo - de acordo com os modos de parecer pelos quais o consumidor comunica-se no meio social contemporâneo. Por mais que seja uma visão parcial, um recorte da realidade que não se pretende totalizante, as representações do ser humano diante da atividade laboral presentes na obra analisada destacam inquietações pertinentes ao nosso tempo de transformações, de um futuro incerto e de um presente complexo e multifacetado.

\section{Referências bibliográficas}

AUGÉ, Marc. Não-lugares: introdução a uma antropologia da supermodernidade. Campinas: Papirus, 1994. BAKHTIN, Mikhail (Volochinov). Marxismo e filosofia da linguagem. São Paulo: Hucitec, 1997.

BARTHES, Roland. "El efecto de realidad". In: El susurro del lenguaje: más allá de la palabra y la escritura. Barcelona: Paidós, 1994.

BAUMAN, Zygmunt. Vida para consumo. Rio de Janeiro: Zahar, 2008.

BOURDIEU, Pierre. A distinção: crítica social do julgamento. São Paulo: Edusp; Porto Alegre: Zouk, 2007. CASAQUI, Vander e RIEGEL, Viviane. "Google e o consumo simbólico do trabalho criativo”. Comunicação, Mídia e Consumo. São Paulo, ESPM, vol. 6, n. 17, novembro de 2009, p.161-180.

CHARAUDEAU, Patrick. Discurso das mídias. São Paulo: Contexto, 2007. 
CHAUÍ, Marilena. "O discurso competente". In: Cultura e democracia: o discurso competente e outras falas. São Paulo: Moderna, 1980, p.3-13.

DEMAZIĖRE, Didier. "Introdução: uma abordagem sociológica sobre a categoria do desemprego". In: GUIMARÃES, N.D.; HIRATA, H. (orgs). Desemprego: trajetórias, identidades, mobilizações. São Paulo: Senac, 2006, p.23-42.

DUBAR, Claude. A crise das identidades: a interpretação de uma mutação. São Paulo: Edusp, 2009.

GALIMBERTI, Umberto. Psiche e Techne: o homem na idade da técnica. São Paulo: Paulus, 2006.

GORZ, André. O imaterial: conhecimento, valor e capital. São Paulo: Annablume, 2005.

HAUG, Wolfgang Fritz. Crítica da estética da mercadoria. São Paulo: Unesp, 1997.

LAZZARATO, Maurizio. As revoluções do capitalismo. Rio de Janeiro: Civilização Brasileira, 2006.

MARX, Karl. "Trabalho estranhado e propriedade privada”. In: ANTUNES, R. (org.). A dialética do trabalho: escritos de Marx e Engels. São Paulo: Expressão Popular, 2004, p.173-195.

MORIN, Edgar. O cinema ou o homem imaginário. Lisboa: Relógio d’Água, 1997.

ORLANDI, Eni Pulcinelli. A Linguagem e o seu funcionamento: as formas do discurso. São Paulo: Pontes, 1987. . Análise de discurso: princípios \& procedimentos. Campinas: Pontes, 2001.

PINTO, Geraldo Augusto. A organização do trabalho no século 20: taylorismo, fordismo e toyotismo. São Paulo: Expressão Popular, 2007.

\section{Notas}

Esta é uma versão modificada de artigo apresentado no VII Seminário do Trabalho, Unesp, Marília, maio de 2010. 